\title{
Recollective experience in the revelation effect: Separating the contributions of recollection and familiarity
}

\author{
DENNY C. LECOMPTE \\ Louisiana State University, Baton Rouge, Louisiana
}

\begin{abstract}
The revelation effect is a phenomenon of recognition memory in which words presented for a recognition decision are more likely to be identified as previously studied if they are initially disguised and are then somehow revealed to the subject. The goal of the present experiments was to determine whether the revelation effect has similar or different influences on the conscious recollection of a previous encounter with a test item and on the feeling of familiarity evoked by a test item. The process-dissociation procedure (Experiment 1) and the remember/know procedure (Experiment 2) were used to achieve this goal. The main findings of these experiments were that revealing an item at test (1) increased the feeling of familiarity associated with that item, especially if it was not previously studied, and (2) decreased conscious recollection of previously studied items. These data narrow the range of potential explanations of the revelation effect.
\end{abstract}

When a recognition test item is initially disguised and then somehow revealed, a subject is more likely to state that it was previously studied than if it had been presented at test without any disguise. This response bias is known as the revelation effect (Luo, 1993; Peynircioğlu Teckan, 1993; Watkins \& Peynircioğlu, 1990). The tendency to identify a revealed item as previously studied applies both to items that were in fact previously studied (targets) and to items that were not previously studied (lures); however, the increase in positive responses to revealed items relative to normally presented items is often slightly more pronounced for lures. Hence, the revelation effect does not improve, and may sometimes impair, subjects' ability to classify items as targets or lures (see Luo, 1993).

\section{The Revelation Effect}

The standard procedure for demonstrating the revelation effect involves presenting a list of words for subjects to remember. At test, half of the items are presented in a normal fashion (e.g., elephant) and subjects indicate whether or not the item was on the earlier list. The other half of the items are initially disguised (e.g., $-l-p$-ant) and are "revealed" before the subjects indicate whether the item was on the list. For instance, over the course of a few seconds, the letters of the test item might be added incrementally until the entire word is visible (e.g., $-l$-p-ant, -lep-ant, elep-ant, elephant). The normal and revealed items are intermingled in the test list, and subjects typically write down each test item correctly before

The author would like to thank Larry Jacoby, Kevin Murnane, and Stephanie LeCompte for their comments on an earlier draft of this manuscript. Requests for reprints should be sent to D. C. LeCompte, Department of Psychology, Louisiana State University, Baton Rouge, LA 70803 (e-mail: pslecom@1suvm.sncc.1su.edu). a recognition decision is made, thereby circumventing the possibility that subjects are misidentifying the test item.

It is worth mentioning that the revelation effect is not limited to the letter-unfolding example cited above. The positive response bias also occurs when the physical appearance of the test item is altered in other ways (e.g., presenting a word with each of its letters rotated $0^{\circ}, 90^{\circ}$, $180^{\circ}$, or $270^{\circ}$ ), when the subject must generate the test item from a clue (e.g., presenting the number 28 as $27-1=$ ?), and when the subject is required to make judgments about an undisguised word (e.g., "How many syllables are in this word?") prior to making a recognition decision about the word (Luo, 1993; Peynircioğlu \& Teckan, 1993; Watkins \& Peynircioğlu, 1990).

The wide variety of techniques that induce the revelation effect demonstrates its robustness and generality; however, that generality does not seem to extend beyond episodic memory. Watkins and Peynircioğlu (1990) failed to generalize the phenomenon to decisions about how typical an exemplar was of its category, about how frequently a word had been encountered in everyday life, and about the likelihood that an unusual string of letters constituted an English word. At present, then, the revelation effect seems to be limited to recognition memory, and it seems reasonable to look to recognition memory to understand this phenomenon.

\section{Recollection and Familiarity}

It has recently been suggested that recognition is not a unitary process (e.g., Jacoby, 1991; Rajaram, 1993). Rather, it has two components. One component reflects the extent to which an individual can consciously recollect having encountered a test item in the past (Rajaram, 1993). The other component reflects the extent to which a feeling of familiarity is associated with a test item (Ra- 
jaram, 1993). To illustrate the distinction, imagine recognizing an acquaintance on the street. This recognition may be accompanied by memories of prior meetings, in which case it is an example of recollection. On the other hand, this recognition may not be accompanied by any memory of a prior meeting; nevertheless, there is a strong feeling of familiarity. Thus, despite knowing that one has met this person before, it is impossible to remember where or when (see Ellis, 1984, pp. 31-32).

A number of experimental manipulations have been shown to affect these two components differently (e.g., Gardiner, 1988; Gardiner \& Java, 1990, 1991; Gardiner \& Parkin, 1990; Jacoby, 1991; Parkin \& Russo, 1993; Rajaram, 1993), thereby lending empirical support to this theoretical distinction between recollection and familiarity. In the present context, the question arises as to how the revelation effect applies separately to recollection and familiarity. It may influence both components to the same or different degrees or it may influence either component exclusively. The answer to this question has theoretical import. False recollection would essentially amount to the creation of false memories (see Loftus, 1993), which would suggest that the revelation effect may be related to phenomena in which postevent information leads to reconstructive memory or confabulation (e.g., Loftus, 1979; Neisser \& Harsch, 1992; Spiro, 1980). On the other hand, false feelings of familiarity would suggest that the revelation effect may be an example of memory misattribution (see Jacoby, Kelly, \& Dywan, 1989), in which case it may be related to phenomena attributed to perceptual fluency or response biases (e.g., Gonzalez, Ellsworth, \& Pembroke, 1993; Jacoby, Allan, Collins, \& Larwill, 1988; Jacoby, Woloshyn, \& Kelley, 1989).

Two procedures have been developed to measure the separate contributions of recollection and familiarity to recognition memory. The process-dissociation procedure infers the separate contributions of recollection and familiarity from subjects' performance in a relatively complicated recognition test. In contrast, the remember/know procedure relies on subjects' introspective reports of recollective experience to separate the contributions of recollection from those of familiarity. Each procedure offers a potentially useful way to examine the revelation effect. The goal of the present research was to use both the process-dissociation procedure and the remember $/$ know procedure so that each methodology might compensate for the flaws of the other, thereby converging on a conclusion about the revelation effect. A brief description of the two procedures and an overview of the present experiments follow.

\section{The Process-Dissociation Procedure}

One procedure for separating recollection and familiarity in recognition memory was recently introduced by Jacoby (1991; see also Jacoby, Yonelinas, \& Jennings, in press). It is known as the process-dissociation procedure. A concrete example will help to illustrate the procedure.
In Jacoby's (1991) Experiment 3, there were three phases. In the first phase, subjects saw a list of words. ${ }^{1}$ In the second phase, they heard a list of words. In the third phase, they were shown a list of words, some of which they had seen, some of which they had heard, and some of which were new. Some subjects were assigned to the inclusion group, which meant they were told to call a word "old" if they had seen it or heard it. Other subjects were assigned to the exclusion group, which meant they were told to call a word "old" only if they had heard it. Thus, subjects in the inclusion condition benefited from any feeling of familiarity associated with an old word, regardless of whether they could recollect its modality of presentation, whereas subjects in the exclusion group could not safely use familiarity as a basis for a recognition decision because, without recollecting presentation modality, they could not determine whether an item should be labeled "old" or "new."

Judgments of the words that had been seen were of primary interest because it was these words that the two groups were instructed to treat differently. Responses for the inclusion group were based on both recollection and familiarity; hence, Jacoby (1991) assumed that performance on the seen words in the inclusion condition $\left(O_{i}\right)$ could be represented by the equation

$$
O_{i}=R+F-R F,
$$

where $R$ represents the probability that a positive response is based on recollection and $F$ represents the probability that a positive response is based on familiarity. Responses for the exclusion group, however, were based on familiarity and a failure of recollection; hence, performance on the seen words in the exclusion condition $\left(O_{e}\right)$ could be represented by the equation

$$
O_{e}=F(1-R) \text {. }
$$

Equation 1 represents items that are both familiar and recollectable, and Equation 2 represents those items that are familiar but not recollectable. Jacoby (1991) therefore argued that the contribution of recollection could be inferred from the difference between the inclusion and exclusion groups in the probability of an "old" response for the items that had been seen. Thus, the formula to compute recollection for the seen words would be

$$
R=O_{i}-O_{e}
$$

Once recollection was computed, familiarity could also be computed using the equation

$$
F=O_{e} /(1-R) .
$$

In Jacoby's (1991) Experiment 3, the probability of calling a seen word "old" was .48 in the inclusion condition and .37 in the exclusion group. Thus, Equation 3 reveals that the probability of calling a word "old" on the basis of recollection was $.48-.37=.11$, and Equation 4 reveals that the probability of calling a word "old" on the basis of familiarity was $.37 /(1-.11)=.42$. 
Notice that if subjects were completely unable to recollect the studied words, recognition would be based entirely on familiarity; hence, probability of recognition in the exclusion condition would not differ from that in the inclusion condition, and, by Equation 3, the estimated recollection score would be 0 . By Equation 4, the estimated familiarity score would then equal the probability of a positive response in the exclusion condition.

Use of the process-dissociation procedure requires a number of assumptions. These have been discussed in detail by Jacoby and his colleagues (Jacoby, Toth, \& Yonelinas, 1993; Jacoby, Toth, Yonelinas, \& Debner, 1994; Jacoby et al., in press; see also Debner \& Jacoby, 1994) and by others (Joordens \& Merikle, 1993). The central assumption of this procedure is that conscious and unconscious processes (viz., recollection and familiarity) make independent contributions to recognition performance, which means that a positive recognition response can occur because an individual recollects the event, finds the event familiar, or both. Jacoby et al. (in press) argue that when conscious and unconscious processes are assumed to be independent, experimental manipulations, such as aging (see Jacoby et al., in press), read versus generate (e.g., Jacoby, 1991; Jacoby et al., 1993), dividing attention (e.g., Jacoby, 1991; Jacoby et al., 1993), and changing presentation modality between study and test (Jacoby et al., in press), yield the same conclusions about these two processes. In contrast, when other relationships between conscious and unconscious processes are assumed (e.g., exclusivity or redundancy), the convergence in findings must be explained as mere coincidence (Jacoby et al., 1993; Jacoby et al., 1994).

The process-dissociation procedure also requires a number of assumptions about how the experimental procedure influences recollection and familiarity: First, under inclusion instructions, if a word is recollected or if it is familiar, the subject will respond positively. Second, under exclusion instructions, if a word is recollected, the subject will respond negatively if it was read rather than heard, which implies that when both conscious and unconscious processes are present, conscious processes dominate unconscious processes. These two assumptions simply specify that subjects are expected to follow instructions, which is typical of most memory experiments. Furthermore, the fact that Jacoby (1991) reports that subjects given exclusion instructions behave like those in a divided-attention condition provides some independent support for these assumptions.

Perhaps the most questionable assumption of this procedure is that recollection and familiarity are invariant across inclusion and exclusion instructions. That is, the probability of responding based on recollection and the probability of responding based on familiarity are identical under inclusion and exclusion conditions; otherwise, Equation 3 could not be derived from Equations 1 and 2. As Jacoby (1991) acknowledges, it might be argued that since recollection is unnecessary for success in the inclusion condition, but essential for success in the exclusion condition, recollection is more probable in the exclusion condition. Of course, if the assumption of invariance across recollection and familiarity is rejected, then the correspondence between the estimates derived from the process-dissociation procedure and other experimental paradigms (see Jacoby et al., in press) would have to be attributed to chance. Thus, the empirical success of the procedure should serve as some support for this assumption.

The validity of these assumptions is crucial to this procedure, but they are not so crucial to the present research because the same question will be asked using a very different procedure that does not share the same assumptions.

\section{The Remember/Know Procedure}

Another procedure, referred to here as the remember/ know procedure, was introduced by Tulving (1985) and developed further by Gardiner (Gardiner, 1988; Gardiner \& Java, 1990, 1991; Gardiner \& Parkin, 1990). In a typical experiment, subjects are first shown a list of words to remember and are later given a test list in which half of the words are from the original list and half of the words are new. The subjects are asked to decide whether each word was on the original list. Whenever the response to a test word is affirmative, the subjects must make another binary decision. For this second decision, the subjects indicate whether they "remember" encountering a word on the list or whether they simply "know" it was on the list despite the fact that they cannot consciously recollect the episode. The "remember" response is treated as a measure of conscious recollection, and the "know" response is treated as a measure of familiarity (see Rajaram, 1993).

Research on this procedure has demonstrated that "remember" and "know" responses can be affected independently. Variables, such as levels of processing ( $\mathrm{Ra}$ jaram, 1993), generation (Gardiner, 1988), and dividing attention at test (Gardiner \& Parkin, 1990), affect "remember" and "know" responses in different ways, thereby demonstrating the potential usefulness of this procedure in measuring recollection and familiarity separately.

This procedure does require the assumption that subjects can accurately report their introspections about recollection. There are those who would question the validity of introspection as a source of experimental data (e.g., Nisbett \& Wilson, 1977), but this assumption is not shared by the process-dissociation procedure, again emphasizing the complementary nature of these procedures.

Another major difference between this procedure and the process-dissociation procedure advocated by Jacoby and his colleagues (e.g., Jacoby et al., in press) concerns the assumption about the relationship between recollection and familiarity. Rather than an independence relationship, the standard interpretation of results from this procedure imply an assumption of exclusivity (cf. Jacoby et al., in press). Because a recognized item must be classified as either remembered or known, it is implied that a given response cannot be the result of both recollection and familiarity. Accordingly, "remember" responses are treated as pure measures of recollection and "know" responses are treated as pure measures of familiarity (see Rajaram, 1993). 
Jacoby et al. (in press) make the case that independence describes the relation between recollection and familiarity better than does exclusivity. Specifically, they cite the fact that an exclusivity assumption does not lead to the same degree of convergence with other experimental paradigms that comes from assuming independence. Furthermore, they show that assuming exclusivity sometimes leads to unusual conclusions (e.g., that priming is solely due to conscious recollection). These problems are eliminated when the results from the remember/ know procedure are recalculated to reflect an assumption of independence between recollection and familiarity.

For the present purposes, the independence assumption will be favored over the exclusivity assumption. Jacoby et al. (in press) argue that only a small recalculation is necessary to convert the remember/know procedure to an independence assumption. Specifically, without any change, "remember" responses should provide a reasonable estimate of recollection if it is assumed that subjects followed instructions and responded "remember" only when they consciously recollected a test item. "Know" responses, however, do not provide a pure measure of familiarity because they only reflect familiarity in the absence of recollection, which excludes the possibility that some "remember" responses were also familiar. To correct this problem, Jacoby et al. (in press) suggest that the number of "know" responses be divided by the number of opportunities that one has to make a "know" response, which is 1 -remember. Thus, familiarity $=\mathrm{know} /(1-\mathrm{re}-$ member). Jacoby et al. refer to this variation in calculation as the independence remember/know (or IRK) procedure.

The second experiment of the present paper employs the remember/know procedure. To be comparable to previous studies, the data will be analyzed by using the standard procedure; to be comparable to the process-dissociation procedure, the remember/know data will also be analyzed using the IRK procedure.

\section{The Present Experiments}

Both the process-dissociation procedure and the remember/know procedure offer ways to analyze the revelation effect in terms of recollection and familiarity; however, the manner in which this analysis is accomplished differs considerably between the two procedures. Consequently, if both procedures converge, providing the same pattern of results with respect to the relative contributions of recollection and familiarity, we can be more confident of that answer. Of course, if they produce different answers, then our assumptions about these procedures may be called into question.

Although the degree of concordance between these two procedures is of some subsidiary interest, the main focus of this research was to determine whether the revelation effect influences recollection, familiarity, or both.

\section{EXPERIMENT 1}

Experiment 1 employed the process-dissociation procedure, closely following the method used by Jacoby
(1991, Experiment 3). Like Jacoby's subjects, the present subjects saw a list of words and then heard a list of words, after which they were given a test that included seen, heard, and new words. There were two major differences. First, the revelation procedure was introduced so that half of the words that had been seen, half that had been heard, and half of the new words were unfolded letter by letter. The other half of each kind was presented normally. Recollection and familiarity estimates were derived separately for normal and revealed words. The second major departure from Jacoby's experiment was that the inclusion and exclusion instructions were varied within subjects (cf. Jacoby et al., in press; Toth, Reingold, \& Jacoby, 1994). Each subject saw a list, heard a list, and took a test, either in the inclusion condition or in the exclusion condition. Each subject then saw a list, heard a list, and took a test in the other condition. Therefore, recollection and familiarity estimates could be derived for each subject, which allowed statistical analysis to be conducted on the derived scores.

\section{Method}

Subjects. The participants were 48 university undergraduates.

Procedure. Each subject sat in front of a computer for presentation of visual stimuli and wore headphones that were attached to the same computer for presentation of auditory stimuli. All instructions were presented on the computer screen. The subjects saw and tried to remember a list of words presented at the rate of one word every 2 sec. Following this list, the subjects heard and tried to remember a list of words spoken at the rate of one word every $2 \mathrm{sec}$. Immediately after the final word of the spoken list, the subjects saw the following instruction, "You are going to see a 6-digit number for a few seconds. Immediately afterward, you will have to recall that number." Six digits then appeared on the screen for 2 sec. After the digits left the screen, the subjects tried to type what they had just seen.

Next, the subjects received instructions about the test. The subjects were told that they would see a series of words, some of which they had seen before, some of which they had heard before, and some of which were new. Subjects in the inclusion condition were told, "If a test item is a word you HEARD or a word you SAW, then say 'YES' to that item. Otherwise, say 'NO.' In other words, say 'YES' to any item you experienced earlier in the experiment." Subjects in the exclusion condition were told, "If a test item is a word you HEARD, then say 'YES' to that item. If you SAW the item, you should say 'NO' to that item. Also, if the item is new, say 'NO.' In other words, only say 'YES' to the item you HEARD."

The subjects were also warned that some of the test words would appear on the screen normally and others would appear letter by letter. The subject pressed a key to begin the test. During the test, all words appeared in the middle of the lower half of the screen. Some words appeared as a whole: All of the letters appeared at the same time. Other words were revealed: These words were preceded by the presentation of eight dashes ("--------"), each of which was replaced by the letters of the test word at the rate of two letters per second. The order in which the letters replaced the dashes was determined randomly and separately for each subject. The subjects were not given the opportunity to guess the test word after each additional letter.

Regardless of presentation condition, as soon as all of the letters of a test word were visible (but not before), the response alternatives appeared on the screen with the appropriate accompanying question. For the subjects in the inclusion condition, the question was, "Did you hear or see testitem?" For the subjects in the exclusion condition, the question was, "Did you hear testitem? (Say 
'no' if you SaW the item)." Under the question were two "buttons," one labeled yes, the other labeled no. The subjects used the computer mouse to move the cursor over the button of their choice and "clicked" the mouse key to make their response.

Following the test, the subjects saw a new list of words. They then heard a new list of words. Finally, they took a second test on their memory for the two new lists. If a given subject had received inclusion instructions for the first list, he or she received exclusion instructions for the second list, and vice versa. In all other respects, the procedure for the second half of the experiment was identical to the procedure for the first half.

Materials and Design. The stimuli were 180 eight-letter words chosen from the Kučera and Francis (1967) norms. They were chosen without regard to frequency. Both at study and test, the words appeared in 32-point Courier font on an Apple Macintosh Classic II computer.

The 180 words were randomly divided in half. One half was used for the first study-and-test phase, and the other half was used for the second study-and-test phase. Both halves were randomly divided into three sets of 30 words. Each set was presented either auditorily or visually, or was not presented. Within each half of the total word pool, each set of 30 words was rotated through the three presentation conditions so that an equal number of subjects encountered each set in each condition. Within a given set, the words were always presented in the same order.

Each of the three sets within each half of the total word pool was further subdivided. For a given set in a given condition, half of the words appeared normally at test, and the other half were revealed letter by letter. The test conditions were counterbalanced so that each word appeared normally to half of the subjects who had seen it, half of the subjects who had heard it, and half of the subjects who had never encountered it before. Likewise, each word was revealed to the other half of the subjects in each of these presentation conditions.

One final counterbalancing manipulation was used that cut across the other six counterbalancing conditions. Specifically, one half of the subjects in each of these six conditions were given inclusion instructions for the first study-and-test phase and exclusion instructions for the second study-and-test phase. The order of inclusion and exclusion conditions was reversed for the other half of the subjects. Consequently, there were 12 counterbalancing conditions.

All subjects were tested on the words in the same order.

\section{Results}

Recognition data. Before estimating and analyzing the recollection and familiarity scores, which are the focus of the present experiment, it is necessary to analyze the raw recognition scores in order to determine (1) whether subjects followed instructions and (2) whether the revelation effect occurred. Failure to meet either of these criteria would invalidate the experiment. These data are illustrated in Figure 1.

First, did the subjects follow the instructions? If they did, then they should be less likely to respond "yes" to a seen word in the exclusion condition than in the inclusion condition, but there should be no difference for the heard or new items. As Figure 1 shows, there was an advantage for the seen words in the inclusion condition, relative to the exclusion condition $[t(47)=5.07, p<.001]$, but no advantage for either the heard condition $[t(47)=$ $1.01, p \approx .31]$ or the new condition $[t(47)<1]$, indicating that the instructions were effective.

The next point concerns the presence of a revelation effect. Collapsed across all conditions, revealed words

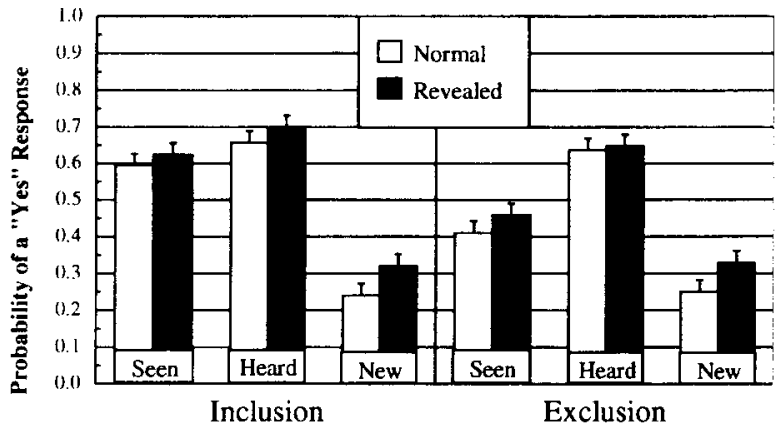

Figure 1. Probability of a "yes" response as a function of revelation condition, type of item, and instructional condition in Experiment 1. Error bars represent $95 \%$ confidence intervals based on the omnibus interaction term of the anabysis of variance.

(.51) elicited "yes" responses more frequently than did normal words $(.47)[t(47)=3.66]$. The revelation manipulation did not interact with the instructional manipulation $(F<1)$, but it did interact with type of item to a marginally reliable extent $\left[F(2,94)=2.92, M S_{\mathrm{e}}=.013\right.$, $p \approx .06]$. Tests of the simple main effects show that there was a statistically reliable revelation effect for the seen words $($ normal $=.50$, revealed $=.54)[t(47)=2.39, p \approx$ $.02]$ and the new words (normal $=.25$, revealed $=.33$ ) $[t(47)=4.89, p<.001]$, but the revelation effect did not reach conventional levels of statistical reliability for the heard words (normal $=.65$, revealed $=.67)[t(47)=1.62$, $p \approx .11]$.

The three-way interaction of revelation, instructions, and type of item was not statistically significant $[F(2,94)$ $\left.=0.63, M S_{\mathrm{e}}=.012, p \approx .53\right]$.

Estimated scores for recollection and familiarity. For each subject, responses to seen words in the inclusion and exclusion conditions were used to estimate recollection and familiarity. As explained in the introduction, recollection is estimated, using Equation 3, as the difference between the inclusion and exclusion conditions in the probability of responding "yes" to a seen word. This score was computed for every subject in the normal and revealed conditions. Likewise, Equation 4 was used to compute an estimate of familiarity for every subject in the normal and revealed conditions.

Figure 2 displays the average recollection and familiarity scores as a function of how the words were presented at test. Because the recollection and familiarity scores were estimated for every subject, they were analyzed statistically.

There was a main effect of component of recognition: Familiarity (.52) played a significantly larger role in the subjects' responses than did recollection $(.18)[F(1,47)=$ $\left.25.50, M S_{\mathrm{e}}=.217, p<.001\right]$. There was no main effect of revelation. Revealed items (.36) elicited more, but not significantly more, "yes" responses than did normal items $(.33)\left[F(1,47)=1.63, M S_{\mathrm{e}}=.028, p \approx .21\right]$.

Most importantly, there was an interaction between component of recollection and revelation $[F(1,47)=5.79$, 


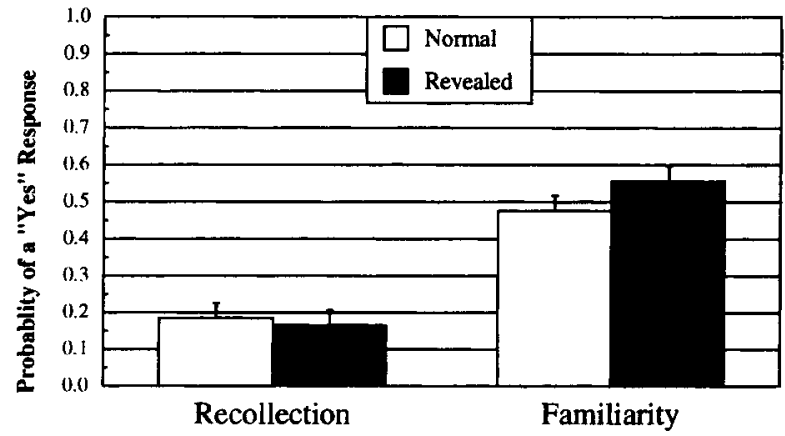

Figure 2. Probability of a "yes" response as a function of revelation condition and component of recognition in Experiment 1. Error bars represent $95 \%$ confidence intervals based on the omnibus interaction term of the analysis of variance.

$\left.M S_{\mathrm{e}}=.020, p \approx .02\right]$. There was no discernible effect of revelation on the recollection scores $[t(47)<1]$; however, there was a large and statistically reliable effect of revelation on the familiarity scores $[t(47)=2.76, p \approx .01]$.

It should be noted that the estimate of familiarity computed by the process-dissociation procedure is based on both targets and lures. By subtracting the false-alarm rate (the probability of responding "yes" to an item that was neither seen nor heard) from the estimate of familiarity, it is possible to estimate the contribution of familiarity to target and lure items separately. There was little difference between the false-alarm rates for the inclusion and exclusion conditions for either normal words $(.24$ and .25 , respectively) or revealed words (.32 and .33 , respectively) $[t(47)<1$, in both cases]; consequently, the average of the inclusion and exclusion conditions were used to compute false-alarm rate.

A comparison of the average false-alarm rates for normal (.25) and revealed (.32) words reveals a significant difference between the two $[t(47)=4.33, p<.001]$; in other words, there was a revelation effect for the lures. In contrast, a comparison of the familiarity estimates for the targets alone shows no discernible difference between the normal $(.23)$ and revealed $(.23)$ conditions $[t(47)<1]$.

\section{Discussion}

The important conclusion to be drawn from Experiment 1 is that revealing items at test increases familiarity but has no detectable effect on recollection. Moreover, the increase in familiarity seems to be more pronounced for new words than for old words. If revelation affects only familiarity, then it is not surprising that there is a smaller effect on targets than on lures, because responses to targets are based on both recollection and familiarity. Thus, the contribution of recollection tends to dilute the influence of familiarity.

As discussed above, there are a number of assumptions necessary for the interpretation of the process-dissociation procedure. Thus, the present conclusion depends on the validity of these assumptions. Although all of these assumptions can be defended to some degree, it would strengthen the present conclusion if the same result could be achieved using a different procedure with somewhat different assumptions.

\section{EXPERIMENT 2}

The results of Experiment 1 indicated that the revelation effect tends to increase the feeling of familiarity but has no discernible effect on recollection. The purpose of Experiment 2 was to try to conceptually replicate these findings by using the remember/know paradigm. Otherwise, it was a typical revelation effect experiment (cf. Watkins \& Peynircioğlu, 1990). The subjects saw a list of words and, at test, new and old words were presented for recognition decisions, but half of the new and half of the old words were unfolded letter by letter. The subjects had the opportunity to guess what the completed word would be after each letter was added (cf. Peynircioğlu \& Teckan, 1993). A recognition decision was made only after the word had been completely revealed. ${ }^{2}$ The only way in which this experiment departed from earlier revelation effect experiments was that whenever subjects indicated that they thought a word had been on the earlier list, they were required to make a remember/know judgment for that word.

\section{Method}

Subjects. The subjects were 148 university undergraduates.

Procedure. Each subject sat in front of a computer for presentation of visual stimuli and wore headphones that were attached to the same computer for presentation of auditory stimuli. All instructions were presented on the computer screen. The subjects were instructed to try to remember a list of words presented visually at the rate of one word every $3 \mathrm{sec}$.

Following list presentation, the subjects were given instructions that explained both the revelation procedure and the remember/know judgments. The instructions were presented on the computer screen one or two sentences at a time. After reading each sentence, the subjects pressed a key to see the next sentence. The complete instructions are presented in the Appendix.

When all of the instructions had been presented, the subjects were given a simple quiz on the difference between a "remember" response and a "know" response. Specifically, the subjects were given the following example: "Your Uncle Dave tells a joke. You are absolutely certain that you have heard the joke before but you can't say where you heard it. Which response is most appropriate here, 'REMEMBER' or 'KNOW'?" If the subjects responded "know," they were shown the message, "Correct! You are very confident that you KNOw the joke, but you don't REMEMBER where you heard it." If they responded "remember," they were told to try again, and they were presented with the example again. The subjects were not allowed to proceed until they responded correctly. Of course, this quiz did not ensure that the subjects understood the instructions, but it did force subjects to think about the distinction, and it provided another opportunity to illustrate that distinction.

After reading the instructions and passing the quiz, the subjects saw the test items one at a time. Some of the test items appeared normally. Other items were disguised and then slowly revealed. Revealed items were initially presented with four of the five letters in the word replaced by dashes (e.g., spoil might appear as -p---). The subjects were encouraged to "try to type the complete word." They could either type something and then press the return key, or they could press the return key without attempting any response. Regardless, no feedback was given. After pressing the return key, a second letter replaced one of the dashes, and the subjects were 
given another opportunity to guess the word. This process continued until the entire word was revealed. The subjects were then required to retype the word and press the return key. ${ }^{3}$ Only then were they allowed to make a recognition decision. The order in which the letters replaced the dashes was determined randomly and separately for each subject.

Immediately following either normal presentation or complete revelation of a word, the subjects were asked, "Was testitem on the list?" and they used the computer's mouse to click on either yes or no, which appeared on the screen below the question. When the subjects responded "no," the next test word was presented. When the subjects responded "yes," they were then asked, "Do you actually REMEMBER seeing testitem on the list, or do you just KNOw that it was on the list?" Again, the subjects responded by using the mouse to click either remember or know on the computer screen.

Materials and Design. The stimuli were 60 five-letter words chosen from the AA category of Thorndike and Lorge's (1944) word count. The words were presented at both study and test in 48-point Courier font on an Apple Macintosh Classic II computer.

The 60 words were randomly divided in half. One half of the subjects studied 30 words, and the other half of the subjects studied the other 30 words. For a given subject, the unstudied words served as lure items on the recognition test. At test, each word was presented normally to one half of the subjects who had studied it and was revealed letter by letter to the other half of the subjects who had studied it. The same was true for the subjects who had not studied the word. Consequently, each of the 60 words was studied and normal for one quarter of the subjects, studied and revealed for one quarter of the subjects, unstudied and normal for one quarter of the subjects, and unstudied and revealed for one quarter of the subjects.

\section{Results}

Raw recognition analysis. Of initial concern is whether or not a revelation effect occurred. Probability of responding "yes" to an item was .52 for the normal items and .57 for the revealed items. This main effect was statistically reliable $[t(147)=4.22, p<.001]$. However, the magnitude of the revelation effect depended on whether the words had been previously studied: Revelation interacted with type of item $\left[F(1,47)=34.44, M S_{e}=.014\right.$, $p<.001]$. More specifically, Figure 3 shows that there was no discernible effect for target words $[t(147)<1]$, but there was an effect for lures $[t(147)=7.81, p<.001]$. The finding of a larger effect for lures is consistent with the results of Experiment 1 and with previous findings (Luo, 1993; Peynircioğlu \& Teckan, 1993; Watkins \& Peynircioğlu, 1990), although the complete absence of a numerical advantage for targets is atypical.

Exclusivity remember/know analysis. The data were analyzed in terms of "remember" and "know" responses assuming an exclusivity relationship between recollection and familiarity. This analysis is consistent with the way that remember/know data are typically reported in the literature (cf. Rajaram, 1993). Thus, the conclusions drawn from this analysis do not depend on the independence assumption or on the procedural assumptions associated with the process-dissociation procedure.

Because the extent of the revelation effect interacted with whether a test item had been seen before, targets and lures are analyzed separately. The remember data are shown in the left panel and the know data are shown in the middle panel. Although Figure 3 showed no discernible

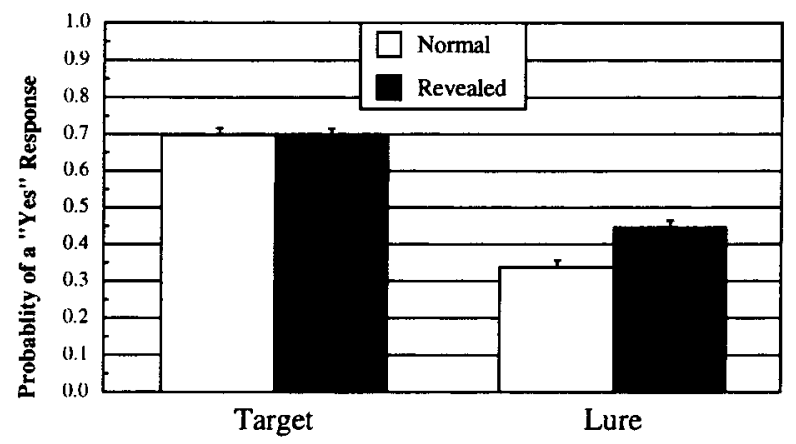

Figure 3. Probability of a "yes" response as a function of revelation condition and type of item in Experiment 2. Error bars represent $95 \%$ confidence intervals based on the omnibus interaction term of the analysis of variance.

revelation effect for the target words, Figure 4 tells a more complex story. Revealing the words at test actually reduced the probability of a "remember" response to a significant extent $[t(147)=4.05, p<.001]$. In contrast, revealing the words at test significantly increased the probability of a "know" response $[t(147)=3.96, p<.001]$.

Some authors (Gardiner, 1988; Gardiner \& Java, 1990; Gardiner \& Parkin, 1990; Parkin \& Russo, 1993; Rajaram, 1993) have analyzed "remember"/"know" responses as an independent variable in an analysis of variance (ANOVA). If this practice were followed in the present case, the interaction between type of response and revelation condition could be computed. Nevertheless, as noted by some of the authors who report such analyses (e.g., Gardiner \& Parkin, 1990; Rajaram, 1993), it is inappropriate because the two responses are not statistically independent. A more defensible alternative analysis was used by Rajaram (1993): For each condition of her experiment, she computed the ratio of "remember" responses to all positive responses on the recognition test. Thus, if some variable increases the relative proportion of "remember" responses, it would be reflected in this measure. This analysis answers roughly the same question as would the ANOVA interaction: that is, does the relation between "remember" and "know" responses vary as a function of revelation condition? A remember/recognition ratio was computed for both the normal (.63) and the revealed targets (.55), revealing that the proportion of "remember" responses was reliably lower for the revealed targets $[t(147)=4.01, p<.001]$. Hence, "remember" and "know" responses are distributed differently as a function of revelation condition.

For lure items, revealing the words at test seemed to increase "remember" responses, but this increase could reasonably have resulted by chance $[t(147)=1.48, p \approx$ .14]. This manipulation resulted in a much larger and statistically reliable increase for "know" responses $[t(147)=$ $5.72, p<.001]$. Because the interaction between type of response and revelation condition could not be computed directly, the remember/recognition ratio described earlier was computed. Although the proportion of "remember" responses was somewhat lower for normal (.37) 


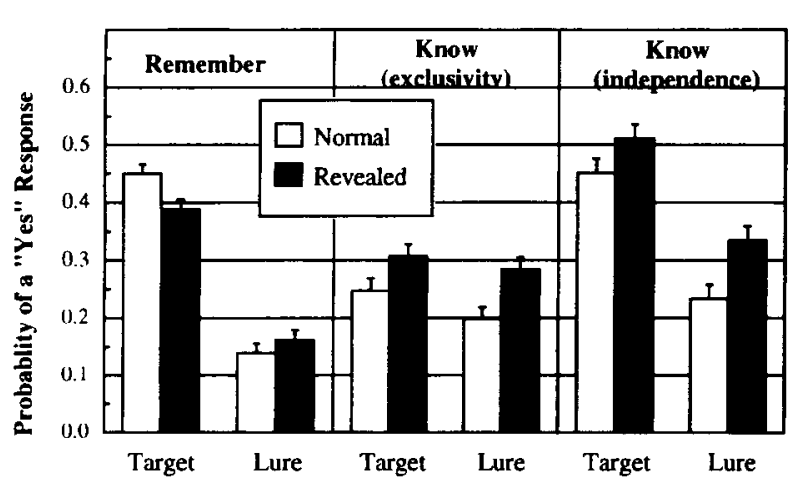

Figure 4. Probability of a "yes" response as a function of revelation condition and type of item for "remember" responses, "know" responses assuming exclusivity, and "know" responses assuming independence in Experiment 2. Error bars represent $95 \%$ confidence intervals based on the omnibus interaction terms of the analysis of variance for each type of response. Thus, error bars cannot be compared across types of response.

than for revealed (.34) items, this difference was not statistically reliable $[t(147)=1.24, p \approx .22]$.

An analysis of the three-way interaction between type of item, revelation, and type of response would be, as mentioned before, inappropriate; therefore, the remember/ recognition ratio was used as the dependent measure and the interaction of type of item and revelation was computed instead. There was a statistically reliable interaction $\left[F(1,147)=3.81, M S_{e}=.033, p \approx .05\right]$, which reflects the fact that revealing the items at test affected targets to a greater extent than it affected lures.

Independence remember/know analysis. In addition to the standard analysis, the remember/know data were reanalyzed with the assumption that recollection and familiarity are independent. This change makes the data more comparable to the process-dissociation procedure in terms of the most fundamental assumption, but the procedural assumptions still differ, thereby preserving the beneficial aspects of using converging operations.

As discussed in the introduction, the "remember" response serves as a reasonably pure estimate of recollection. Hence, under an independence assumption, the analysis of the "remember" responses would be identical to those under the exclusivity assumption (see the left panel of Figure 4). Under an independence assumption, an estimate of familiarity is derived by dividing the "know" responses by the opportunities available to provide a "know" response (viz., 1 -remember). Thus, familiarity $=$ know $/(1-$ remember $)$.

For each subject, a familiarity score was computed for normal and revealed targets and normal and revealed lures. These data are shown in the right panel of Figure 4. There was a reliable effect of revelation on familiarity for both targets and lures $[t \mathrm{~s}(147)=3.29$ and 5.60 , respectively, $p \mathrm{~s}<.005]$. Although the revelation effect was numerically larger for lures than for targets, the interaction of revelation and type of item failed to reach conventional levels of statistical reliability $[F(1,147)=2.68$,
$\left.M S_{\mathrm{e}}=.024, p \approx .10\right]$. The independence analysis of the remember/know procedure yields the same conclusion as the exclusivity analysis: Revelation increases the feeling of familiarity.

\section{Discussion}

These results suggest that for a word that was actually seen on the studied list, revealing the word before a recognition decision is made increases the feeling of familiarity associated with that word, but the revelation process makes the word harder to consciously recollect. Why revelation increases the feeling of familiarity will be discussed later, but a reasonable explanation of why revelation might decrease conscious recollection can be found in the encoding specificity principle (see Tulving, 1983). This principle states that memory depends on the extent to which conditions at study match conditions at test. If the "remember" response is seen as a purer measure of memory than overall recognition (see Rajaram, 1993), then it would be expected that revealed items would be harder to remember because they are less similar to the original studied items (cf. the transfer-appropriate processing framework, Roediger, Weldon, \& Challis, 1989).

Disguising and then revealing a word that was not actually on the studied list substantially increased the feeling of familiarity associated with that word. No reliable effect was found, however, for those unstudied words that the subjects claimed to consciously recollect. The failure to find an effect in this condition is unsurprising because subjects cannot actually recollect words they did not see.

\section{GENERAL DISCUSSION}

The goal of the present experiments was to determine whether the revelation effect differentially influenced the recollection and familiarity components of recognition. Experiment 1 used the process-dissociation framework introduced by Jacoby (1991). In this experiment, the subjects saw some words and heard other words. Recollection and familiarity were estimated from the subjects' responses to instructions to respond either "yes" or "no" to words they had seen. These estimates indicated that revealing a word at test increased the feeling of familiarity associated with unstudied words but had no discernible effect on the feeling of familiarity associated with studied words or on conscious recollection of any words.

Experiment 2 used the remember/know procedure (see Rajaram, 1993) to conceptually replicate Experiment 1 . The results were analyzed using two separate assumptions about the relationship between recollection and familiarity. Under both the exclusivity assumption and the independence assumption, "remember" responses were defined as measures of conscious recollection. Under the exclusivity assumption, "know" responses were defined as measures of familiarity; under the independence assumption, "know" responses were divided by 1 -"remember" responses in order to estimate familiarity. Under both assumptions, this experi- 
ment showed that revealing a word at test increased feelings of familiarity. Under the independence assumption, this effect was true regardless of whether a word had been studied at test; however, under the exclusivity assumption, the increase in familiarity was of only marginal reliability for studied words.

Regardless of assumptions, revealing a word was found to decrease conscious recollection of studied words, which, as mentioned earlier, is consistent with the encoding specificity principle (Tulving, 1983). However, revealing a word was not found to have any discernible effect on the recollection of unstudied words, which seems appropriate because it is not possible to consciously recollect an unstudied word. Thus, the results of Experiments 1 and 2 seem to converge on the finding that the revelation effect increases responses based on familiarity but does not increase responses based on recollection.

The only difference in the findings between the two experiments concerns the effect of familiarity on studied words. The process-dissociation procedure showed no evidence of an effect, whereas the remember/know procedure did show evidence for such an effect. This difference seems minor and may be due to small variations in methods between the experiments. Further research would be needed to determine whether this difference in results is inherent to the differences in the experiments or to differences in the process-dissociation procedure and the remember/know procedure.

\section{THEORETICAL IMPLICATIONS OF THE PRESENT FINDINGS}

How does the main conclusion of these experimentsthat the primary effect of revealing a word at test is to induce a feeling of familiarity - bear on attempts at theoretical explanations of the revelation effect? Peynircioğlu and Teckan (1993) tested some of the more obvious hypotheses about the effect. First, they explored whether increased time and effort on the disguised items brought about the revelation effect; but, in three experiments, their manipulations of effort and time failed to influence the magnitude of the revelation effect. In four other experiments, Peynircioglu and Teckan varied the degree to which the test items were associated with each other on the assumption that highly associated words might prime each other and enhance the revelation effect; however, no such enhancement was observed. Because their hypotheses did not hold up to empirical scrutiny, the present findings do not bear on their conclusions. Nevertheless, it might be mentioned that Peynircioglu and Teckan seem to assume that the revelation effect influences familiarity, an assumption that is now supported empirically.

The present findings are more relevant for an explanation put forward by Luo (1993). Although he did not test his ideas empirically, Luo speculated as to the theoretical underpinnings of the revelation effect. He tried to describe the phenomenon in terms of a misattribution process (see Jacoby, Kelly, \& Dywan, 1989, and Jacoby
\& Whitehouse, 1989) in which ease of perception or conceptualization (Luo invoked both perceptual and conceptual fluency to account for extant experiments) is erroneously attributed to a prior encounter with the item. Luo stated that subjects' failure to recognize that the increased fluency of the revealed items derives from the additional exposure during the revelation process; consequently, they believe that they have seen the item before.

At first glance, the present data seem consistent with the fluency hypothesis. Jacoby (1991; Jacoby, Kelly, \& Dywan, 1989; see also Rajaram, 1993) has argued that fluency should affect familiarity without influencing conscious recollection, which is the main conclusion from the present data. Nevertheless, there are several serious problems with the fluency explanation of the revelation effect. First, the fluency hypothesis has no a priori means for explaining why revealing a target item in the present Experiment 2 actually decreased conscious recollection. A second problem with the fluency hypothesis is that it could just as easily have explained a reversed revelation effect. The interpretation of the fluency hypothesis put forth by Luo (1993) rests on the post hoc assumption that subjects treat their perception of the word during revelation as distinct from their perception of the word during their actual recognition decision. This assumption may seem plausible for the letter-unfolding manipulation used in the two experiments reported here, but it seems less plausible for some of the revelation manipulations used by Watkins and Peynircioğlu (1990), such as presenting words upside down. If this distinctperceptions assumption is not made, then the fluency explanation would predict that revealing an item would decrease "yes" responses because the revealed items would be more difficult to perceive than would the normal items (cf. Watkins \& Peynircioğlu, 1990). The flexibility of this hypothesis with respect to the revelation effect detracts substantially from its explanatory power.

The third and most serious problem with the fluency hypothesis is its failure to explain why the revelation effect seems restricted to judgments of episodic recognition (Watkins \& Peynircioğlu, 1990). Fluency explanations, in contrast, have not been limited to judgments of recognition memory. For example, the false-fame effect- the increase in subjects' tendency to judge an ordinary name as famous if it was previously studied (Jacoby, Woloshyn, \& Kelley, 1989) - has been attributed to the increased fluency with which the ordinary name is perceived (Jacoby, 1991). If judgments of fame are affected by fluency, it seems reasonable to expect that judgments of category typicality, word frequency, and lexicality should also be affected by fluency. Yet, Watkins and Peynircioğlu (1990) found no hint of a revelation effect in these conditions. In light of these points, it would seem premature to accept a fluency explanation of the revelation effect.

Thus, no theoretical explanation is completely consistent with the extant data. No new hypothesis is offered here because to do so without also presenting empirical tests of that hypothesis would qualify as mere guess- 
work. Nevertheless, the present data do represent an advance in our understanding of the revelation effect. The finding that the revelation effect creates an illusion of familiarity without creating an illusion of recollection rules out any explanations that might posit reconstructive memory or confabulation. Hence, subsequent efforts to explain this unusual phenomenon can more easily avoid theoretical dead ends.

\section{REFERENCES}

DeBner, J. A., \& JACOBY, L. L. (1994). Unconscious perception: Attention, awareness, and control. Journal of Experimental Psychology: Learning, Memory, \& Cognition, 20, 304-317.

ELLIS, H. D. (1984). Practical aspects of face memory. In G. L. Wells \& E. F. Loftus (Eds.), Eyewitness testimony: Psychological perspectives (pp. 12-37). Cambridge: Cambridge University Press.

GARDINER, J. M. (1988). Functional aspects of recollective experience. Memory \& Cognition, 16, 309-313.

GARDINER, J. M., \& JAVA, R. I. (1990). Recollective experience in word and nonword recognition. Memory \& Cognition, 18, 23-30.

GARDINER, J. M., \& JAVA, R. I. (1991). Forgetting in recognition memory with and without recollective experience. Memory \& Cognition, 19, 617-623.

Gardiner, J. M., \& Parkin, A. J. (1990). Attention and recollective experience in recognition memory. Memory \& Cognition, 18, 579583.

Gonzalez, R., Ellsworth, P. C., \& Pembroke, M. (1993). Response biases in lineups and showups. Journal of Personality \& Social Psychology, 64, 525-537.

JACOBY, L. L. (1991). A process dissociation framework: Separating automatic from intentional uses of memory. Journal of Memory \& Language, 30, 513-541.

Jacoby, L. L., Allan, L. G., Collins, J. C., \& Larwill, L. K. (1988). Memory influences subjective experience: Noise judgments. Journal of Experimental Psychology: Learning, Memory, \& Cognition, 14, 240-247.

JaCOBY, L. L., Kelley, C. M., \& Dywan, J. (1989). Memory attributions. In H. L. Roediger III \& F. I. M. Craik (Eds.), Varieties of memory and consciousness: Essays in honour of Endel Tulving (pp. 391422). Hillsdale, NJ: Erlbaum.

JaCoBy, L. L., Toth, J. P., \& Yonelinas, A. P. (1993). Separating conscious and unconscious influences of memory: Measuring recollection. Journal of Experimental Psychology: General, 122, 139-154.

Jacoby, L. L., Toth, J. P., Yonelinas, A. P., \& Debner, J. A. (1994). The relationship between conscious and unconscious influences: Independence or redundancy? Journal of Experimental Psychology: General, 123, 216-219.

JACOBY, L. L.,. \& WhiteHouse, K. (1989). An illusion of memory: False recognition influenced by unconscious perception. Journal of Experimental Psychology: General, 118, 126-135.

JACOBY, L. L., WolOSHYN, V., \& KeLleY, C. (1989). Becoming famous without being recognized: Unconscious influences of memory produced by dividing attention. Journal of Experimental Psychology: General, 118, 115-125.

JACOBY, L. L., Yonelinas, A. P., \& Jennings, J. M. (in press). The relationship between conscious and unconscious (automatic) influences: A declaration of independence. In J. Cohen \& J. W. Schooler (Eds.), Scientific approaches to the question of consciousness. Hillsdale, NJ: Erlbaum.

JoORdENS, S., \& MERIKLE, P. M. (1993). Independence or redundancy? Two models of conscious and unconscious influences. Journal of Experimental Psychology: General, 122, 462-467.

KuČERA, H., \& FranCIS, W. N. (1967). Computational analysis of present-day American English. Providence, RI: Brown University Press.

LofTus, E. F. (1979). Eyewitness testimony. Cambridge, MA: Harvard University Press

Loftus, E. F. (1993). The reality of repressed memories. American Psychologist, 48, 518-537.
Luo, C. R. (1993). Enhanced feeling of recognition: Effects of identifying and manipulating test items on recognition. Journal of Experimental Psychology: Learning, Memory, \& Cognition, 19, 405-413.

Neisser, U., \& Harsch, N. (1992). Phantom flashbulbs: False recollections of hearing the news about Challenger. In E. Winograd \& U. Neisser (Eds.), Affect and accuracy in recall: Studies of "flashbulb" memories (pp. 9-31). New York: Cambridge University Press.

NisbetT, R. E., \& WiLson, T. D. (1977). Telling more than we can know: Verbal reports on mental processes. Psychological Review, 84, 231-259.

Parkin, A. J., \& Russo, R. (1993). On the origin of functional differences in recollective experience. Memory, 231-237.

Peynircioǧlu, Z. F., \& TeCKan, A. I. (1993). Revelation effect: Effort or priming does not create the sense of familiarity. Journal of Experimental Psychology: Learning, Memory, \& Cognition, 19, 382-388.

RAJARAM, S. (1993). Remembering and knowing: Two means of access to the personal past. Memory \& Cognition, 21, 89-102.

Roediger, H. L., III, Weldon, M. S., \& Challis, B. H. (1989). Explaining dissociations between implicit and explicit measures of retention: A processing account. In H. L. Roediger III \& F. I. M. Craik (Eds.), Varieties of memory and consciousness: Essays in honour of Endel Tulving (pp. 3-41). Hillsdale, NJ: Erlbaum.

SPIRO, R. J. (1980). Accommodative reconstruction in prose recall. Journal of Verbal Learning \& Verbal Behavior, 19, 84-95.

THORNDIKE, E. L., \& LORGE, I. (1944). The teacher's word book of 30,000 words. New York: Teachers College Press, Columbia University.

TOTH, J. P., REINGOLD, E. M., \& JACOBY, L. L. (1994). Toward a redefinition of implicit memory: Process dissociations following elaborative processing and self-generation. Journal of Experimental Psychology: Learning, Memory, \& Cognition, 20, 290-303.

Tulving, E. (1983). Elements of episodic memory. New York: Oxford University Press.

Tulving, E. (1985). Memory and consciousness. Canadian Psychologist, 26, 1-12.

WatKIns, M. J., \& PEYnircroĞLU, Z. F. (1990). The revelation effect: When disguising test items induces recognition. Journal of Experimental Psychology: Learning, Memory, \& Cognition, 16, 1012-1020.

\section{NOTES}

1. In actuality, Jacoby (1991) presented some of the words as anagrams that the subjects were required to solve. This detail was left out of the description of Jacoby's experiment to facilitate exposition and comparison with the present data. This omission does not affect the explanation of the process-dissociation procedure.

2. Because the words are revealed letter by letter, it is possible that subjects make their actual recognition decision as soon as they have enough letters to allow identification of the word. Nevertheless, previous research on the revelation effect has shown that the revelation effect occurs even when identification of the word is more or less instantaneous - as in the rotated letter experiments of Watkins and Peynircioğlu (1990) - which suggests that the time between identification of the revealed word and a decision about whether the word is old or new is unimportant.

3. Experiment 2 was actually conducted before Experiment 1 , and, between the two experiments, other research indicated that requiring subjects to guess after each letter was presented was not important to the magnitude of the revelation effect; hence, this requirement was not included in what is reported here as Experiment 1.

\section{APPENDIX \\ Instructions Given to the Subjects in Experiment 2}

You will now see a series of words. Half of the words on the test were on the list you just studied. Half are new words. If you recognize a word, you will use the mouse to "click" on the word YES. If you do not recognize the word, click on the word NO. Some of the test words will appear normally. Other words will be presented as puzzles. The puzzle-words will be presented first with 1 letter, then with 2 letters, then with 3 letters, 
and so on until the whole word is revealed. In other words, the task is a little like "Wheel of Fortune" or "Hangman." At each level of the puzzle (that is, 1 letter, 2 letters, etc.), you should try to guess what the word is. It doesn't matter if you are wrong. Even if you guess incorrectly, you can guess again at the next level. Eventually, the entire word will be revealed and you will simply retype this word. We are interested in how quickly you can guess the word.

Don't forget: After each test word is completely presented, you will have to judge whether or not it was on the study list. Additionally, as you make your decision about recognizing a word, you should keep in mind the following: Often when REMEMBERING a previous event or occurrence, we consciously recollect and become aware of aspects of that previous experience. For instance, if you think about a movie you've seen, you can consciously recollect some of the scenes and perhaps some of the dialogue. At other times, we simply KNOW that something has occurred before, but we are unable to consciously recollect anything about its occurrence. In other words, although we KNOW (and are completely confident) that we experienced an event, we cannot recollect what we experienced. We are inter- ested in looking at which items you REMEMBER and which items you KNOW without remembering.

In this experiment, each time you say "YES" to a test item, you will be asked whether you REMEMBER the item or if you just KNOW it was on the list. You should say REMEMBER only if you can consciously recollect seeing the word in the list. Otherwise, respond KNOW. You can tell that you consciously recollect an item if you remember such things as its physical appearance, how it was presented, what you thought of when you saw the word, or perhaps something you noticed in the room as you saw the word. Any specific memory of the event will do. If, on the other hand, you have a strong feeling that a word was on the list, but you cannot remember anything about its presentation, respond kNOW.

Finally, keep in mind that a kNOw response does not necessarily mean low confidence. For instance, you can be sure that you have seen a particular person before, even though you cannot remember where or when. You just kNOw that you've seen them.

(Manuscript received July 18, 1994; accepted for publication July 21,1994 .) 